DATASTAR - Data-Star, 5th Floor Plaza Suite, 114 Jermyn Street, London SW1Y 6HJ. Tel 0719305503.

MAXWELL ONLINE-BRS Colleague, Achilles House, Western Avenue, London W3 0UA. Tel 081992 3456. Fax 0819937335 .

DIALOG-Dialogue Informations Services, PO Box 8, Abingdon, Oxford OX13 6EG. Tel 0865326326.

CURRENT CONTENTS-Institute for Scientific Information, Brunel Science Park, Brunel University, Uxbridge UB8 3PQ. Tel 0895230085.

ESA-IRS - C P 64 Via Galileo Galilei, 00044 Frascati, Italy. STN INTERNATIONAL-PO Box 2465, D-7500 Karlsruhe 1, Germany.

THE BRITISH LIBRARY: ONLINE SEARCH CENTRE -25 Southampton Buildings, London WC2A 1AW. Tel 071 3237477 .

MEDICAL INFORMATION SERVICE-Document Supply Centre, Boston Spa, Wetherby LS23 7BQ. Tel 0937 546000/84343. Fax 0937546333.

CD-ROM SUPPLIERS

SILVERPLATTER INFORMATION INC-10 Barley Mow Passage, Chiswick, London W4 4PH. Tel 0819958242. Fax 0819955159

GLOBAL COMMUNICATIONS-Albermarle House, Osborne Road, Southsea, Hants PO5 3LB. Tel 0705291866. Fax 0705821677.

OPTECH LTD-East Street, Farnham, Surrey GU9 7XX. Tel 0252714340 . Fax 0252711121

NETWORK SERVICES

JANET (Joint Academic Network)--JANET Network Executive, c/o Rutherford-Appleton Laboratory, Chilton, Didcot OX11 0QX. Tel 0235445637.
DIALPLUS - GNS, BT, Network House, Brindley Way, Hemel Hempstead HP3 9RR. Tel 0800181555

1 Scheidt SS, Goldstein H, Blackburn LS. Application of the office or home computer to searching the medical literature. I Am Coll Cardiol 1986:8: $1211-7$

2 Wallingford KT, Humphreys BL, Selinger NE, Siegel ER. Bibliographic retrieval: a survey of individual users of MEDLINE. MD Comput 1990; $166-71$.

Ludwig L, Mixter JK, Emanuele MA. User attitudes toward end-user literature searching. Bull Med Libr Assoc 1988;76:7-13.

4 McKibbon KA, Haynes RB, Dilks CJ, Ramsden MF, Ryan NC, Baker L, et al. How good are clinical MEDLINE searches? A comparative study of clinical end-user and librarian searches. Comput Biomed Res 1990;23: 583-93.

5 Wyat J Computer-based knowledge systems. Lancet 1991;338:1431-6.

6 Wyatt J. Use and sources of medical knowledge. Lancet 1991;338:1368-73.

Bonham MD, Nelson LL. An evaluation of four end-user systems for searching MEDLINE. Bull Med Libr Assoc 1988;76:22-31.

8 Garfield JM, Flanagan H, Fox J. A comparison of two microcomputer-based programs for bibliographic retrieval and formatting. I Clin Monit 1989;5: $177-85$

9 Simon FA. A comparison of two computer programs for searching the medical literature. Fournal of Medical Education 1988;63:331-3.

10 Rosenberg V. Pro-Search, Biblio-Links and Pro-Cite: software to gather and manage scientific and technical information. Biotechniques 1991;10:796-7.

11 Schmid K, Bohmer G. Reference master: a microcomputer-based storage and retrieval system for bibliographic references. Int f Biomed Comput 1987;20: $107-21$.

BMf 1986;292:1643-5

3 Wertz RK. CD-ROM. A new advance in medical information retrieval. $¥ A M A$ 1986;256:3376-8.

14 Bowler RP, Becker CE Computer searching for occupational medicine $f$ Occup Med 1986;28:370-2.

15 Haynes RB, McKibbon KA, Fitzgerald D, Guyatt GH, Walker CJ, Sackett DL. How to keep up with the medical literature. V. Access by personal computer to the medical literature. Ann Intern Med 1986;105:810-6.

16 Walker CJ, McKibbon KA, Haynes RB, Ramsden MF. Problems encountered by clinical end users of MEDLINE and GRATEFUL MED. Bull Med Libr Assuc 1988; 79:67-9.

17 Nussey SS, Lyon E. The clinical 'end user'-a neglected resource in patient care? I R Coll Physicians Lond 1990;24:119-22.

18 Haynes RB, McKibbon KA, Walker CJ, Ryan N, Fitzgerald D, Ramsden MF. Online access to MEDUINE in clinical settings. A study of use and usefulness. Amn Intern Med 1990;112:78-84.

(Accepted 5 May 1993)

\title{
Neuroleptics, learning disability, and the community: some history and mystery
}

\author{
David Manchester
}

Recent papers have again highlighted the consistently high use of neuroleptic agents among people with a learning disability, despite the lack of good evidence to support their role in this population for behaviour management and despite the risks of such medication. Evidence suggests, however, that prescribing habits have remained relatively unchanged; the reasons for this are poorly understood. Given the lack of understanding about the factors contributing to such drug use, and the possibility that use of neuroleptics will increase as people with learning disabilities move into the community, there seems a clear need for clinical guidelines to cover the prescribing and monitoring of neuroleptics within this group. Such guidelines should also ensure that reviews, using reliable measures of treatment efficacy, are carried out regularly.

For the sake of clarity the term learning disability is used throughout this paper and replaces the various other terms (for example, mental handicap, mental retardation, and developmental disability) used to describe the same client population in some of the papers mentioned.

Clinical Psychol Services, Clifton Hospital, York YO3 6RD

David Manchester, clinical psychologist in learning disabilities

BMY 1993;307:184-7 estimated that most people with a learning disability receive one or more drugs to control behaviour, including stimulants, anticonvulsants, antidepressants, major tranquillisers, and anxiolytics. ${ }^{5}$ Overall, those most commonly used in managing behaviour are neuroleptics. In a recent review of 168 people with learning disabilities living in hospital, $49 \%$ were receiving neuroleptic medication. ${ }^{3}$

Standard psychopharmacology text books assert that the clearest indication for the use of neuroleptic medication is to treat psychiatric disorders, where the symptoms they aim at decreasing are causing suffering and disability for the client. ${ }^{\circ}$ Estimates for serious psychiatric disorders in people with learning disabilities range from $8 \%$ to $15 \% .^{7}$ One recent American survey of over 40000 people with learning disabilities living in hospital or in the community noted a prevalence for psychoses of $6.68 \%$ in people under 22 years of age and of $5.69 \%$ in people aged 22 years and over. ${ }^{8}$ The incidence of shizophrenia alone has been estimated as $3.4 \%$ among hospital residents. ${ }^{\circ}$

Although there is a consensus that the prevalence of psychiatric illness in people with learning disabilities is greater than that in the general population, the true rate is notoriously difficult to verify. This is partly because people with severe to profound disability are unlikely to be able to give adequate or reliable self reports, and partly because most studies have concentrated on hospital populations, which are by definition unrepresentative of the client group as a whole. Studies on this topic have also been criticised for using vague 
As more people with learning disabilities move into the community, more general practitioners will become involved in their health needs

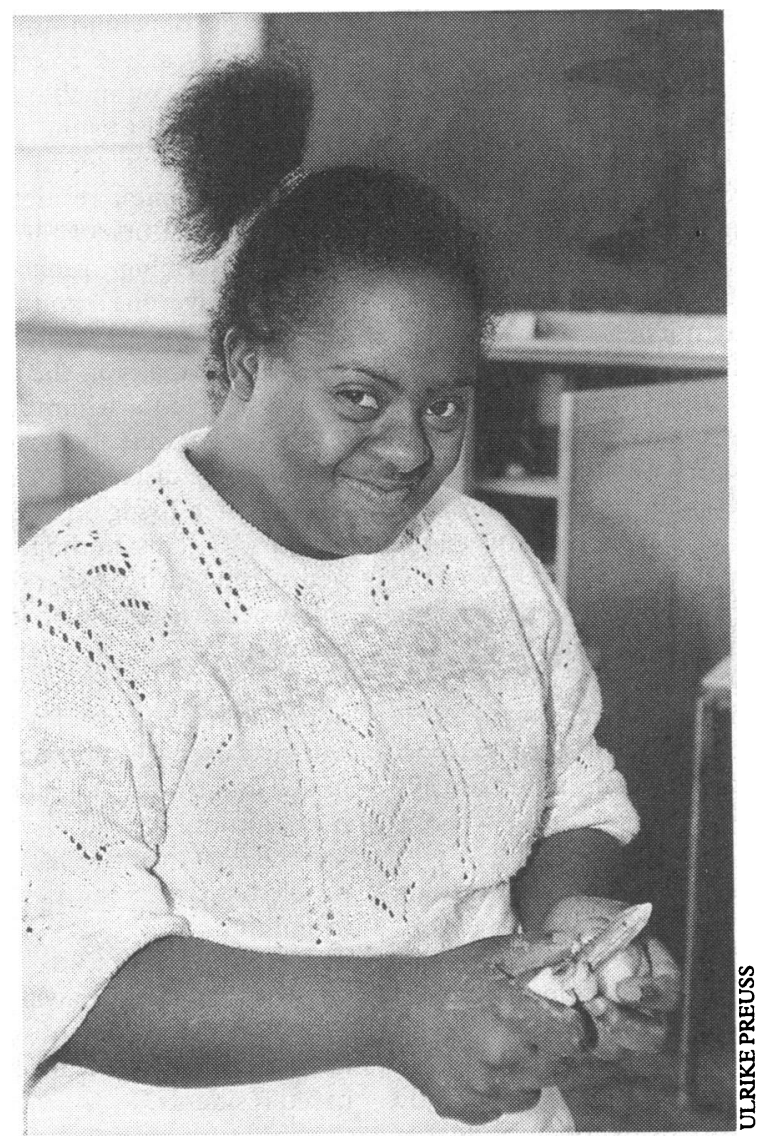

diagnostic criteria and for the relaxed interpretation of diagnostic guidelines. ${ }^{10}$

Even though mental illness is thought to be more prevalent in people with learning disabilities, psychotropic drug use in this group exceeds even the most generous estimates of mental illness warranting such medication. Although there is little doubt that neuroleptics offer considerable relief to those suffering from a psychotic illness, prescribing in people with learning disabilities often continues in the absence of any psychiatric diagnosis. A study of a hospital in Hong Kong for people with moderate and severe learning disabilities found that only one of the 69 subjects receiving an antipsychotic drug had a formal psychiatric diagnosis. " Similarly, in England, of 505 hospital residents studied and for whom a psychiatric diagnosis could be ruled out, $183(36 \%)$ were found to be receiving psychotropic medication, predominantly neuroleptics. ${ }^{12}$

The main reason for giving neuroleptics to people with learning disabilities is not the effective management of psychoses but rather the control of disruptive behaviour such as aggression, self injury, and destruction of property. ${ }^{13}$ Yet there is a conspicuous lack of good evidence supporting the role of neuroleptics for the control of maladaptive behaviours in this population. Studies purporting to show their efficacy have been criticised for poor methodology, including lack of controls, the use of clinical impression rather than the reliable measurement of behaviour to assess outcome, and a failure to measure the effects of medication on other behaviours in order to facilitate a reasonable riskbenefit analysis. ${ }^{14}$ Aman, writing as part of the American Psychiatric Association's task force on treatments of psychiatric disorders, stated that it was still not clear whether the neuroleptics have a specific effect on certain maladaptive behaviours, or whether the clinical changes that occur are simply part of a more general sedative action. ${ }^{15}$ One Australian psychiatrist has noted that the common prescription of psychotropic medication for those with learning disabilities seems to be based more on custom than on empirical study. ${ }^{16}$ In some cases these drugs may worsen already inappropriate behaviours. ${ }^{17}$

Drug therapies can also allow for the problem to be seen as primarily the individuals, rather than viewing it within a wider environmental and social context. For example, those factors that make the problem more likely to occur could be examined with a view to ameliorating these instead or as well. ${ }^{18}$ This view can also mean that proved behavioural interventions ${ }^{19}$ go untried and opportunities to help the person learn more adaptive alternative behaviours such as functional communication, ${ }^{20}$ social skills, ${ }^{21}$ and relaxation training ${ }^{22}$ are missed.

The long term use of neuroleptics exposes the client not only to an increased risk of acquiring the potentially irreversible condition of tardive dyskinesia, but also to the potentially fatal neuroleptic malignant syndrome. One Australian study of 53 patients with a learning disability found that $34 \%$ of those clients who had been exposed to neuroleptics had symptoms that suggested tardive dyskinesia, and $30 \%$ had a mild tremor. Also, the $60 \%$ of subjects who were being maintained on neuroleptic drugs at the time of the study had been receiving them for a mean of 14 years.'

Recently the issue of neuroleptic drug use and side effects has started to come before the courts, with large awards being made in America to people treated with neuroleptics who have gone on to develop tardive dyskinesia. ${ }^{23}$ According to one reviewer, "The 20 to 25 law suits involving rights related to medication have consistently re-affirmed the right of [learning disabled] people to be free from unnecessary or excessive medication, and have stipulated that medications are not to be used as punishment, or for staff convenience, or at levels that interfere with habilitation programming." ${ }^{24}$

\section{Non-medical factors associated with use of neuroleptics}

In attempting to understand the continued high levels of use of neuroleptics found in learning disabled people, researchers have implicated various nonmedical factors in their continued use. These include the type of environment the person lives in, poor staffing levels in residential accommodation, the lack of recreational opportunities, the availability of a physician, and the training level of caregivers. ${ }^{\prime}$ Although these factors are intuitively appealing, the evidence supporting a role for any of them in prescribing patterns is conflicting. For example, many believe that more staff for each client group would lead to a reduction in the need for such drugs as staff would have more time to interact with and train clients, resulting in a reduction in difficult behaviour. Yet one investigation into the determinants of maladaptive behaviours in institutionalised learning disabled people found that worsening the staff:client ratio by increasing the number of clients for each direct care staff member was associated with a decrease in maladaptive behaviour. ${ }^{18}$ Also, solely increasing staffing levels does not seem to have the beneficial effects that might be expected. Increasing the number of staff working with a given client group has been found to have a marginal to nonexistent effect on improvements in both staff performance and client behaviour. ${ }^{25}$

Approaches that consist only of educating staff or involving psychiatrists and physicians with a special interest in learning disabilities may also be unlikely to effect major change in use of neuroleptics. Even when the number of doctors is increased and well intentioned prescribing philosophies intent on reducing use exist, there is not necessarily any decrease in prevalence of prescribing, although dosage levels may decrease. ${ }^{326}$ 
For example, in Linaker's study $49 \%$ of 168 institutionalised learning disabled adults were found to be receiving neuroleptics. Yet during the previous five years it had "been the policy of the medical administration at the institution to reduce or eliminate psychotropic drugs whenever possible. However an investigation at the same institution ten years earlier when the population was $50 \%$ higher showed exactly the same frequency $(49 \%)$ of psychotropic drug use." ${ }_{3}$

Similarly, in a British study nursing staff were aware of the importance of reviewing the use of psychotropic drugs, had an increased awareness of the potential risks associated with them, especially in patients with a learning disability, and had received training wherein they were encouraged to "eschew" such medication. Although a reduction in dosage was noted between the time of the study and four years previously, 47 of the 243 patients $(24 \%)$ found to be taking neuroleptic drugs had not been receiving these drugs four years before and had been started on them during the interim. Of these 47 patients, 27 were diagnosed as having a behaviour disorder, which, as the authors point out, is "not a category which automatically lends itself to the prescription of anti-psychotic medication." 26

Finally, it has also been suggested that prescribing factors in institutions may be influenced by nonmedical factors such as the availability of a physician or psychiatrist. Although a high correlation between neuroleptic drug dosage and the availability of a physician may reflect physicians' tendency to quickly administer drugs, Linaker cautions that "the study design does not exclude the opposite conclusion, that the physicians of the institution are adequately distributed, according to need." ${ }_{3} \mathrm{He}$ also points out that while the negative relation between level of activity and neuroleptic drug dosage noted in his study may suggest that increasing activities would result in lower dosages, it could also be explained by clients with less disturbing behaviour being easier to activate and tending to receive less medication in any case.

\section{Neuroleptics and the community}

To date, most studies of neuroleptic drug use in learning disabilities have concentrated on prevalence within hospitals, given the large captive population and the ease of access for researchers. After deinstitutionalisation, however, the more pressing issue is the effect of community care on future neuroleptic use. Although type of residence (that is, environment) has been considered to influence prescribing patterns, the evidence for this view has been conflicting. Some researchers have found comparable levels of psychoactive drug use in community setting $\mathrm{s}^{27}$ but others have found community use to be considerably less than hospital use..$^{2429}$ An early review of five community studies concluded that the use of psychotropic and anticonvulsant drugs in community settings was comparable to that in institutions. ${ }^{30}$ However, one of these studies was only of children and another ${ }^{31}$ has since been discredited. ${ }^{32}$

Though research shows large differences in prevalence of prescribing between hospitals and the community, the effects of environment on prescribing practice remain equivocal, for those clients with fewest behavioural problems are usually living in the community in any case. Therefore less of a perceived need for psychotropic medication would be expected in community residences to begin with, and a drug review after a big move into the community from hospital showing a large difference in prescribing rates between the two settings need not reflect any change in prescribing habits.

To illustrate this, imagine a hospital with 100 clients, 60 of whom are receiving neuroleptic drugs. After two years of resettlement 50 of the most able clients are living in the community; these include the 40 who were not taking neuroleptics and 10 who were. A survey of prevalence at this point would find that $100 \%$ of hospital residents were taking neuroleptics, compared to $20 \%$ of those in the community, yet the true prescribing rate has remained unchanged. Interestingly, one group of British researchers who followed the community move of 81 people with a learning disability in the west midlands found that "of the 64 people for whom full information was obtained, $24(37.5 \%)$ were receiving anti-psychotic drugs two years before discharge, $25(39 \%)$ at discharge, and 25 $(39 \%)$ after living in the community for at least six months." ${ }_{33}$ This finding would certainly suggest that neuroleptic drug use does not necessarily decrease solely because people no longer live in institutions.

Another possible explanation for high rates of neuroleptic use in the community is that neuroleptics in this population are given for reasons in addition to those usually used in hospitals, possibly because less maladaptive behaviours are considered more serious in the community. Thus, behaviours that may at one time have been tolerated as the norm or not seen as problematic in institutions become more conspicuous in community settings. One study found that use of major tranquillisers was significantly related to hyperactivity and withdrawal among community based residents and to violent or destructive behaviour, and level of clients' physical development among institution based residents. ${ }^{24}$

\section{The general practitioner's increasing role}

As more people with learning disabilities move into the community, more general practitioners are going to become involved in meeting their health needs, in keeping with the philosophy of community care. A major reason for consultations is likely to be the pharmacological management of maladaptive behaviours. General practitioners are unlikely to have specialised in either learning disability or behavioural pharmacology. ${ }^{16}$ They are also less likely to be aware of alternative management approaches.

General practitioners may find some referrals to be financially motivated, as caregivers choose to attempt to control disruptive behaviour by the relatively inexpensive means of medication. Similarly, fundholding general practitioners may be discouraged to buy in costly assessments by psychiatrists or psychologists and these may in turn lead to even costlier interventions, especially if they have not budgeted for what is essentially an emergent need. One commentator has asserted quite plausibly that "the solutions which psychopharmacology offers have the potential for resolving fiscal dilemmas and for obscuring tough political choices, as much as for alleviating client centred problems." ${ }^{34}$

One argument that is occasionally used to justify giving psychotropic medication for maladaptive behaviours is that these drugs bring the behaviour sufficiently under control for other less restrictive and more positive procedures to be used. However, it has been suggested that this very emphasis on medication may replace other more appropriate, but also more difficult, management strategies, ${ }^{1}$ and others have cautioned that short term benefits may become long term treatment in the absence of careful monitoring programmes. $^{35}$

\section{Use of guidelines}

Regardless of just what factors are contributing to the high use of neuroleptics in people with learning 
disabilities, a consensus seems to be emerging on the need for clinical protocols to control for the prescribing, monitoring, and reviewing of behavioural drugs in learning disability. Researchers contend that these drugs ought to be given as part of an individualised habilitation plan and "according to guidelines which ensure that they are carefully monitored for both their intended and unintended effects." ${ }^{24}$ Others have suggested that the construction of a well conceived drug evaluation strategy will not only improve medical practice but also increase adaptive behaviours, increase the likelihood of successful community placement, and decrease the risk of serious side effects. ${ }^{36}$ Similar sentiments have been echoed elsewhere. ${ }^{161737}$

The effectiveness of such guidelines in decreasing the use of pharmacological treatment in this population has already been shown. ${ }^{38}{ }^{39}$ Reductions gained after the introduction of approaches requiring systematic monitoring and evaluation have also been maintained after eight years of follow up. ${ }^{40}$

\section{Conclusion}

As increasing numbers of people with a learning disability move into the community, there is little to suggest that those already taking neuroleptics will stop, some evidence to suggest that those not taking them may get them, and considerable evidence to suggest that most of those receiving them should not be doing so. Attempts to explain prescribing levels in terms of non-medical factors have been conflicting, and there is a poverty of good longitudinal research to explain many of the findings made to date.

Intuitively appealing interventions such as increased staffing levels, increased staff education, greater recreational activities, or better housing may not be the panaceas we might all like them to be. In addition, the possibility that use of neuroleptic drugs may become even more commonplace in the community because of the greater cost of alternative management strategies, the financial pressures of fundholding general practitioners and carers, and the possible utilisation of neuroleptics for a wider range of behaviours warrants cautious attention and future research.

In the absence of adequate knowledge about those variables controlling neuroleptic use, there seems a clear need for guidelines to ensure that adequate riskbenefit analyses are carried out at assessment and that medication, if given, is properly monitored, with regular reviews built into the process. Such reviews ought to include reliable measures of not only the behaviour for which the drug was given but also of those behaviours which the drug is known to affect.

Grateful thanks go to Dr R Banks, Professor W Fraser, Maria and Lisa Thompson, and L Haggar for reading and comments.

1 Sachdev PS. Psychoactive drug use in an institution for intellectually handicapped persons. Med J Austr 1991;155:75-9.

2 Ballinger BR, Ballinger C, Reid AR, McQueen E. The psychiatric symptoms, diagnoses and care needs of 100 mentally handicapped patients. $\mathrm{Br} f$ Psychiatry 1991;158:251-4.

3 Linaker $O M$. Frequency of and determinants for psychotropic drug use in an institution for the mentally retarded. Br $\mathcal{}$ Psychiatry 1990; 156:525-30.

4 Ryan M. Drug use in NSW institutions-innovation or inertia? Austr NZ $f$ Dev Disabil 1991;17:177-81.
5 Whitman T, Donald A, Spence B, Spence H. Current issues in behaviou modification with mentally retarded persons. In? Matson JL, ed. Handbook of behaviour modification with the mentally retarded. New York: Plenum 1990:9-41.

6 Harrison-Reid P. The use of drugs in psychiatry. In: Sanger D, Blackman D, eds. Aspects of psychopharmacology. London: Methuen, 1984

7 Deb S, Hunter D. Psychopathology of people with mental handicap and epilepsy. II. Psychiatric illness. Br f Psychiatry. 1991;159:826-30.

8 Jacobson JW. Do some mental disorders occur less frequently among persons with Mental Retardation? Am f Ment Retard 1990;94:596-602.

9 Heaton-Ward WA. Psychosis in mental handicap. Br f Psychiatry 1977;130 525-33.

10 Meadows G, Turner L, Campbell S, Reveley M, Murray R. Assessing schizophrenia in adults with mental retardation. $B r$ F Psychiatry 1991;158: schizop.

11 Fan TW. Prescribing in mental handicap hospitals. Br f Psychiatry 1991;158: $282-3$

12 Clarke DJ, Kelley S, Thinn K, Corbett JA. Psychotropic drugs and mental retardation. 1. Disabilities and the prescription of drugs for behaviour and for epilepsy in three residential settings. F Ment Defic Res 1990;34:385-95

13 Chadsey-Rusch J, Sprague RL. Maladaptive behaviours associated with neuroleptic drug maintenance. Am J Ment Retard 1989;93:607-17.

14 Aman MG. Psychoactive drugs in mental retardation. In: Treatment issues and innovations in mental retardation. New York: Plenum, 1983:455-513.

15 Aman MG. Neuroleptics. In: Treatments of psychiatric disorders. Washington, DC: American Psychiatric Association, 1989:71-7.

16 Parker J. Developmentally disabled, doubly disadvantaged. Med f Austr 1991;155:68-71.

17 Burgio L, Page T, Capriotti R. Clinical behavioural pharmacology. Methods for evaluating medications and contingency management. $\mathcal{f}$ Appl Behav Anal 1985;18:45-59.

18 Duker PC, Van Druenen C, Karel J, Han O. Determinants of maladaptive behaviour of institutionalised mentally rtarded individuals. Am $\mathcal{f}$ Ment Defic 1986;91:51-6.

19 Gardner WI, Cole CL. Aggression and related conduct difficulties. In: Matson $\mathrm{J}$, ed. Handbook of behaviour modification with the mentally retarded. New York: Plenum, 1989:225-48.

20 Bird F, Dores P. Moniz D, Robinson J. Reducing severe aggressive and selfinjurious behaviours with functional communication training. Am $\mathcal{f}$ Ment Retard 1989;94:37-48

21 Matson JL, Stephens RM. Increasing appropriate behaviour of explosive chronic psychiatric patients with a social skills training package. Behav Mod 1978;2:61-76.

22 Harvey JR. The potential of relaxation training for the mentally retarded. Ment Retard 1979 April:71-6.

23 Shriqui CL, Bradwejn J, Jones B. Tardive dyskinesia. Legal and preventive aspects. Can F Psychiatry 1990;35:576-80.

24 Intagliata J, Rinck C. Psychoactive drug use in public and residential facilities for mentally retarded persons. Psychopharmacol Bull 1985;21:268-78.

25 Felce D, Repp AC, Thomas M, Ager A, Blunden R. The relationship of staff:client ratios, interactions, and residential placement. Res Dev Disabil 1991;12:315-31

26 Wressel SE, Tyrer SP, Berney TP. Reduction in antipsychotic drug dosage in mentally handicapped patients. A hospital study. Br J Psychiatry 1990;157: 101-6.

27 Martin JE, Agran M. Psychotropic and anticonvulsant drug use by mentally retarded adults across community residential and vocational placements. App Res Ment Retard 1985;6:33-49.

28 Hill BK, Ballow EA, Bruininks RH. A national study on the prescribed drugs in institution and community residential facilities for mentally retarded people. Psychopharmacol Bull 1985;21:279-84.

29 Zaharia ES, Struxness L. Comparative survey of drug use in a community Zaharia ES, Struxness L. Comparative survey

30 Agran M, Martin JE. Establishing socially validated drug research in community settings. Psychopharmacol Bull 1985;21:285-91.

31 Davis VJ, Cullari S, Breuning SE. Drug use in community foster group homes. In: Bruening SE, Poling A, eds. Drugs and mental retardation. Springfield, Illinois: Charles C Thomas: 1982 .

32 Holden C. NIMH finds a case of "serious misconduct." Science 1987;235: 1566-7.

33 Thinn K, Clarke DJ, Corbett JA. Psychotropic drugs and mental retardation. 2. A comparison of psychoactive drug use before and after discharge from hospital to community. 7 Ment Defic Res 1990;34:397-407.

34 Mouchka $S$. Issues in psychopharmacology with the mentally retarded. Psychopharmacol Bull 1985;21:262-7.

35 Gualtieri CT, Keppel JM. Psychopharmacology in the mentally retarded and a few related issues. Psychopharmacol Bull 1985;21:304-10.

36 Keppel JM, Gualtieri CT. Monitoring psychopharmacology in programs for the retarded. In: Treatments of psychiatric disorders. Washington, DC: the retarded. In: Treatments of psychiatric

37 Rinck C, Guidry J, Calkins C. Review of states' practices on the use of psychotropic medication. Am I Ment Retard 1989;93:657-68.

8 Hancock RD, Weber SL, Kaza R, Her KS. Changes in psychotropic drug use in long term residents of an ICF/MR facility. Am f Ment Retard 1991;96: 137-41.

39 James $\mathrm{DH}$. Monitoring drugs in hospitals for the mentally handicapped. $\mathrm{Br} \mathcal{F}$ Psychiatry 1983;142:163-5.

40 Briggs R. Monitoring and evaluating psychotropic drug use for persons with mental retardation: a follow-up report. Am F Ment Retard 1989;93:633-9.

(Accepted 29 April 1993) 